\title{
Construction of Photovoltaic Power Generation-storage System Using an Inverter with SiC FET and SBD
}

\author{
Takeo Oku ${ }^{1, *}$, Yuji Ando ${ }^{1}$, Masashi Yasuda ${ }^{2}$, Yasuhiro Shirahata ${ }^{1}$, \\ Kazufumi Ushijima $^{3}$, Mikio Murozono ${ }^{4}$ \\ ${ }^{1}$ Department of Materials Science, the University of Shiga Prefecture, Japan \\ ${ }^{2}$ Collaborative Research Center, the University of Shiga Prefecture, Japan \\ ${ }^{3}$ ArumoTech Corporation, Japan \\ ${ }^{4}$ Clean Venture 21 Corporation, Japan \\ *Corresponding Author: oku@mat.usp.ac.jp
}

Copyright $\bigcirc 2017$ by authors, all rights reserved. Authors agree that this article remains permanently open access under the terms of the Creative Commons Attribution License 4.0 International License

\begin{abstract}
A power storage system using spherical $\mathrm{Si}$ solar cells, lithium-ion battery and a direct current-alternating current (DC-AC) converter was constructed. A small and light inverter system was developed by combining a maximum power point tracking charge controller, direct current-direct current (DC-DC) converter, and DC-AC converter. Performance evaluation of the inverter system with $\mathrm{SiC}$ field-effect transistors (FET) and Schottky barrier diodes (SBD) was carried out, and the DC-AC conversion efficiencies and their stability of the inverter were improved compared with those of the ordinary Si-FET/SBD based inverter.
\end{abstract}

Keywords Inverter, SiC, Solar Cell, Spherical Si, FET

\section{Introduction}

A total of about 1.2 billion people are said to live without the benefit of electricity in south Asia and Africa, and 1 billion people live under the unstable electricity. They use about 3 trillion dollars per year to buy fuels such as kerosene and candles, and they are also not good for human health. Portable, self-standing power generation/storage systems are one of the promising to solve these problems. Solar cells provide electricity and produce no carbon dioxide and hazardous waste gases causing global warming. Spherical Si solar cells can reduce the consumption of $\mathrm{Si}$ compared with the conventional crystal Si solar cells [1-8]. Flexible, light solar cells were also manufactured using silicon spheres with a diameter of $\sim 1 \mathrm{~mm}$ with a pn junction at the sphere surface [9-11]. The spherical Si solar cells are one of the candidates for the portable electric source.

Although most of the power electronic converters are based on silicon $(\mathrm{Si})$ semiconductor, performance of the $\mathrm{Si}$ devices is approaching the theoretical limits of the silicon crystal. Therefore, power devices consisting of semiconductors with wide band gap energies such as silicon carbide ( $\mathrm{SiC})$ and gallium nitride are needed. These wide gap semiconductors have superior features compared with Si for the performance of power electronic systems. Higher electrical breakdown voltage, lower 'on'-resistance $\left(R_{o n}\right)$ and higher thermal conductivity provide small size, improved efficiency of components for high power switching and less heating, respectively. Therefore, the $\mathrm{SiC}$ devices have smaller size and lighter weight [12-16], compared with the ordinary Si devices. In addition, the $\mathrm{SiC}$ device has higher efficiencies for high power switching devices with high frequencies, which can operate at higher temperatures of $\sim 600^{\circ} \mathrm{C}$ without much change in their electrical properties compared with the Si devices $\left(\sim 200^{\circ} \mathrm{C}\right)$. The $\mathrm{SiC}$ devices are one of the leading candidates of next generation power devices [17-22].

The purpose of the present work was to construct and characterize a photovoltaic power generation/storage system using spherical Si solar cells, lithium-ion battery and a direct current-alternating current (DC-AC) converter using $\mathrm{SiC}$ devices and maximum power point tracking (MPPT) charge controller, considering self-standing, portable emergency power sources under low electric power of $\sim 150$ W. The SiC field-effect transistor (FET) and SiC Schottky barrier diodes (SBD) were introduced in the present inverter. Since spherical Si panels are lighter and more flexible compared with the ordinary flat $\mathrm{Si}$ solar panels, the spherical Si solar cells were used as the power sources in the present work. To use and accumulate the generated electricity effectively, Li ion batteries were also connected with the present system. Conversion efficiencies and device losses were analyzed and discussed, which were compared with an ordinary Si-based converter. 


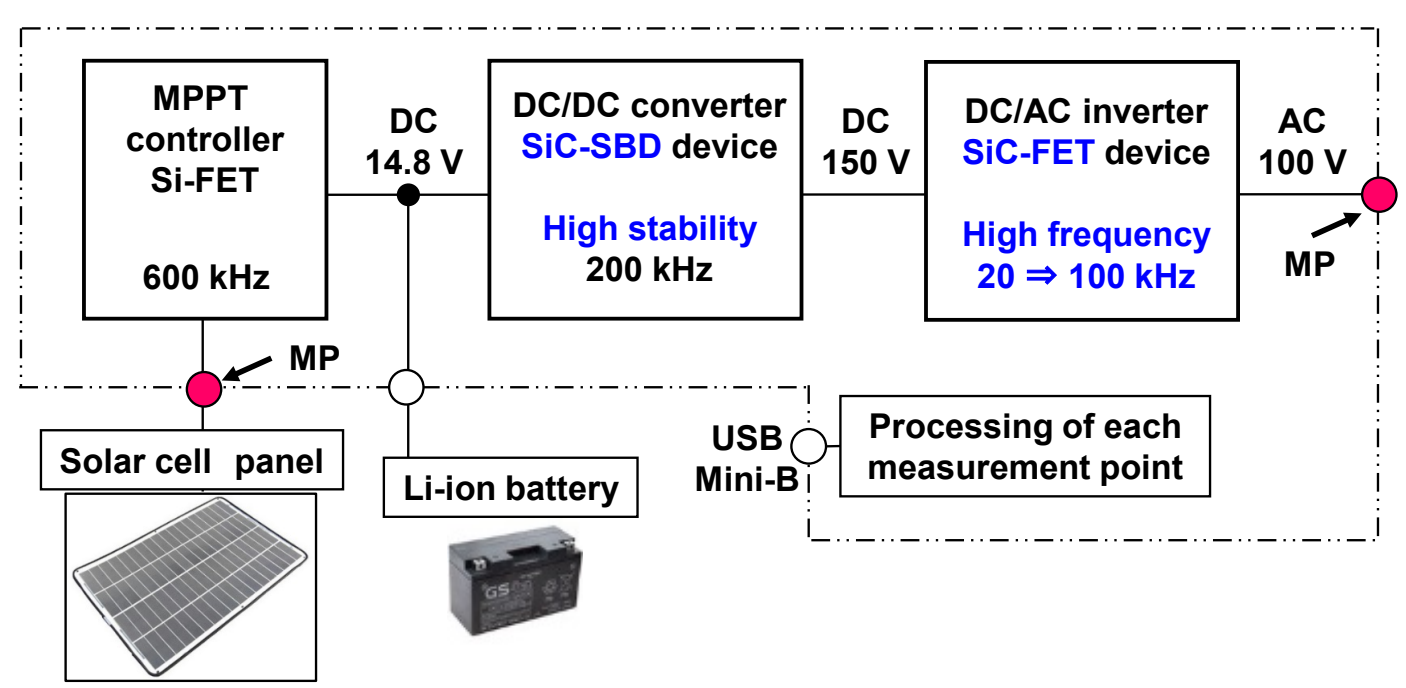

Figure 1. Schematic illustration of the experimental setup of SiC-FET inverter using solar cells and Li ion battery.

\section{Experimental}

A schematic illustration of the basic experimental setup for the present inverter system is shown in Fig. 1. Spherical silicon solar cells (Clean venture 21, CVFM-0540T2-WH) were used as a power source for the inverter operation, and 4 solar cell panels were connected to the inverter in parallel. A Li ion battery (O’Cell, IFM12-200E2) was used for storage of the generated electricity. Measuring points (MP) are indicated in Fig. 1. Details of the spherical Si solar cells and $\mathrm{Li}$ ion battery are described in the previous paper [22-24]. The generated voltage was almost constant ( 14 V), and the power and current were strongly dependent on the intensity of the natural sunlight. As a reference system, measurements using conventional Si inverter (Daiji Industry, SXCD-300) with Si-FET (Fairchild, FQPF16N25C) and MPPT controller (EPsolar, Tracer-2215BN) were also performed as described in the previous work [23,24].

The input power and output power of the inverters were measured by the power meter (Hioki, PW3336). The measurement interval was set as $200 \mathrm{~ms}$, and the measured data were averaged for each $1 \mathrm{~min}$. The load was controlled in response to changes in solar radiation, and the input power was controlled to the inverter. The power efficiencies, temperature, humidity (Hioki, LR5001) and solar radiation (Uizin, UIZ-PCM01-LR) were measured at the same time by synchronizing them. The conversion efficiency of each inverter was calculated from the input and output powers.

\section{Results and Discussion}

A schematic illustration and a photograph of the constructed inverter in the present work are shown in Fig. 2. The size and weight of the SiC-inverter with the MPPT were reduced down to $1260 \mathrm{~cm}^{3}$ and $1.3 \mathrm{~kg}$ (Fig. 2(a)), respectively, which is almost half size of the previous inverter system [23,24]. A photograph of the present constructed SiC-inverter is shown in Fig. 2(b). 4 SiC-SBDs (Rohm, SCS210AJ) were introduced in the part of DC-DC conversion to stabilize the performance under the elevated temperatures, as indicated by blue square lines. To reduce the volume and weight of the inverter, 4 SiC-FETs (Rohm, SCT2120AF) were introduced in the part of DC-AC conversion, as indicated by red square lines. Improvement of the conversion efficiency of the inverter was also expected.

Measured data as a function of time are shown in Fig. 3. These data correspond to one another, and the load was 59 $\mathrm{W}$. The amount of solar radiation during the measurements is shown in Fig. 3(a). The amount of solar radiation between 11 and 15 were extremely unstable because of the cloudy weather. Temperatures and humidity during the measurements are shown in Fig. 3(b). Although drastic change of the solar radiation power is observed in Fig. 3(a), the temperatures and humidity were almost constant during the measurements.

Figure 3(c) is variations in conversion efficiency of the inverter $\left(\eta_{\text {inv }}\right)$, generated photovoltaic power $\left(P_{p v}\right)$, battery output power $\left(P_{b a t}\right)$ and DC-AC output power $\left(P_{a c}\right)$ during the measurements. The $P_{p v}$ power strongly depended on the amount of solar radiation, and the $P_{b a t}$ values were fluctuated by the $P_{p v}$ values. DC-AC conversion efficiencies were not affected by the photovoltaic power and battery power, and the $\eta_{i n v}$ values are stably constant during the measurements.

DC-AC conversion efficiencies of the present SiC-FET and Si-FET inverters supplied by spherical Si solar cells are shown in Fig. 4, which indicates the $\eta_{i n v}$ values as a function of output AC power of the inverters. Efficiencies of both inverters increased as the output power increased, and the conversion efficiency of the $\mathrm{SiC}$-inverter was totally larger compared with that of conventional Si-inverter. 

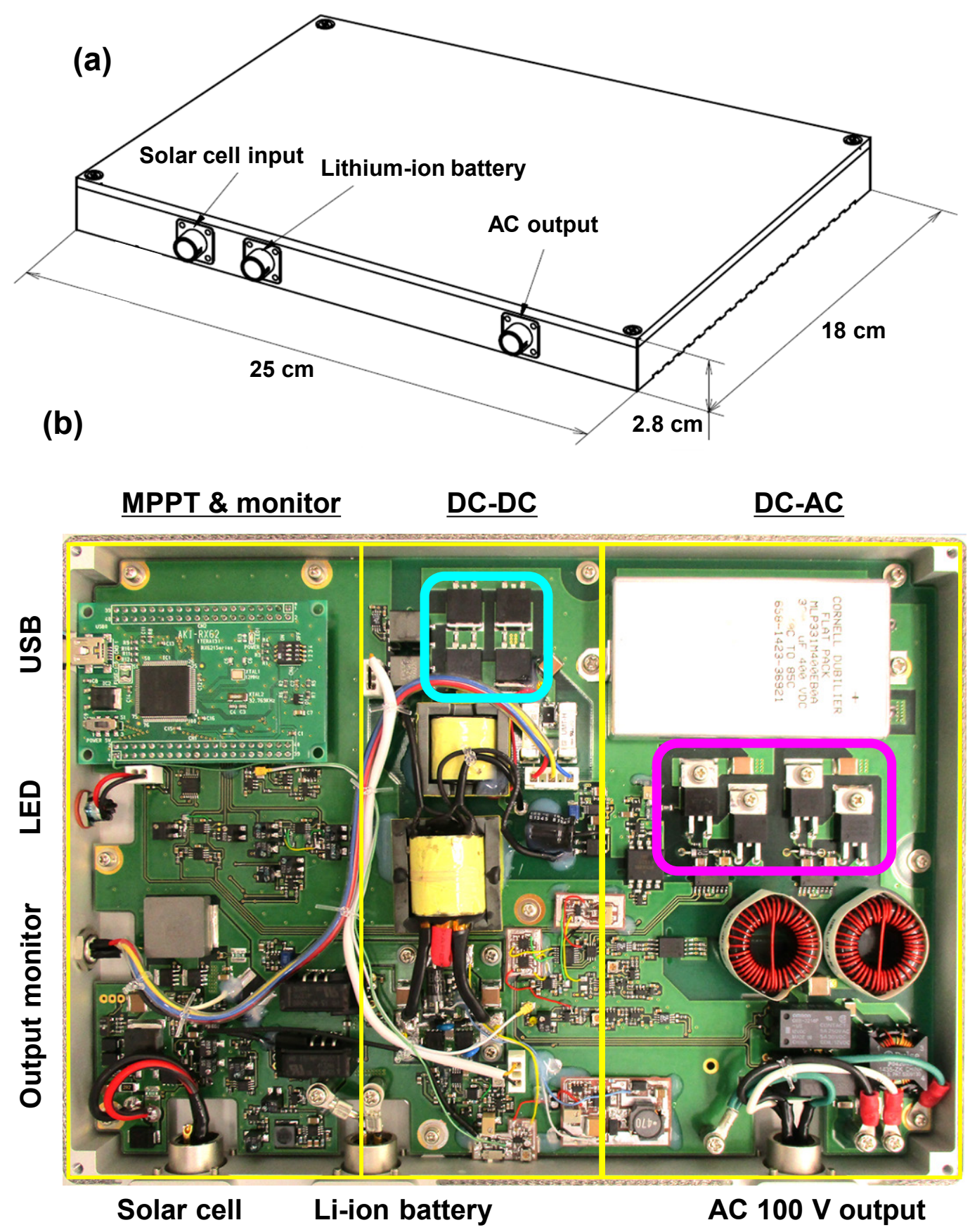

Figure 2. (a) Schematic illustration and (b) photograph of the present SiC-inverter. 

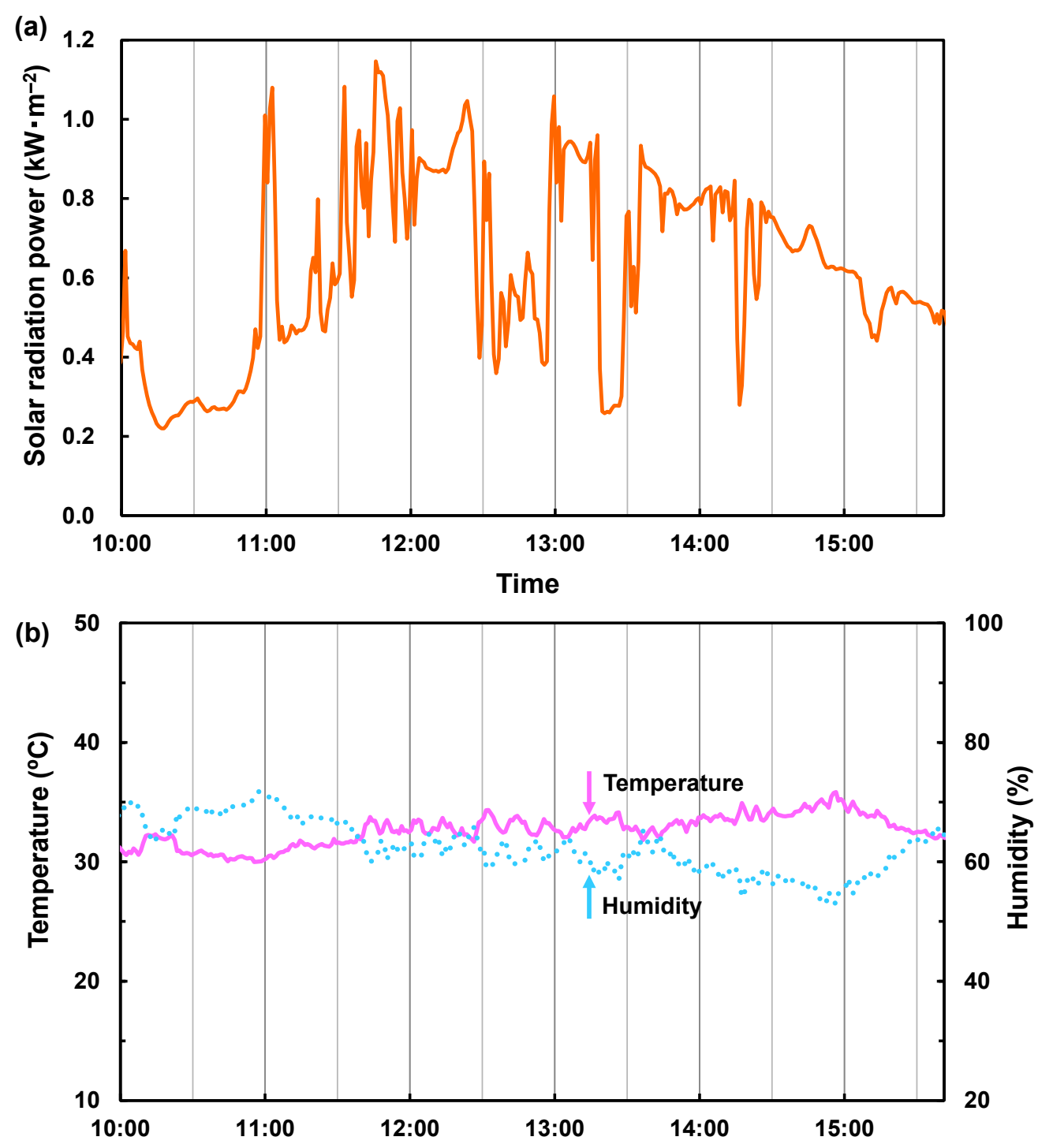

Time

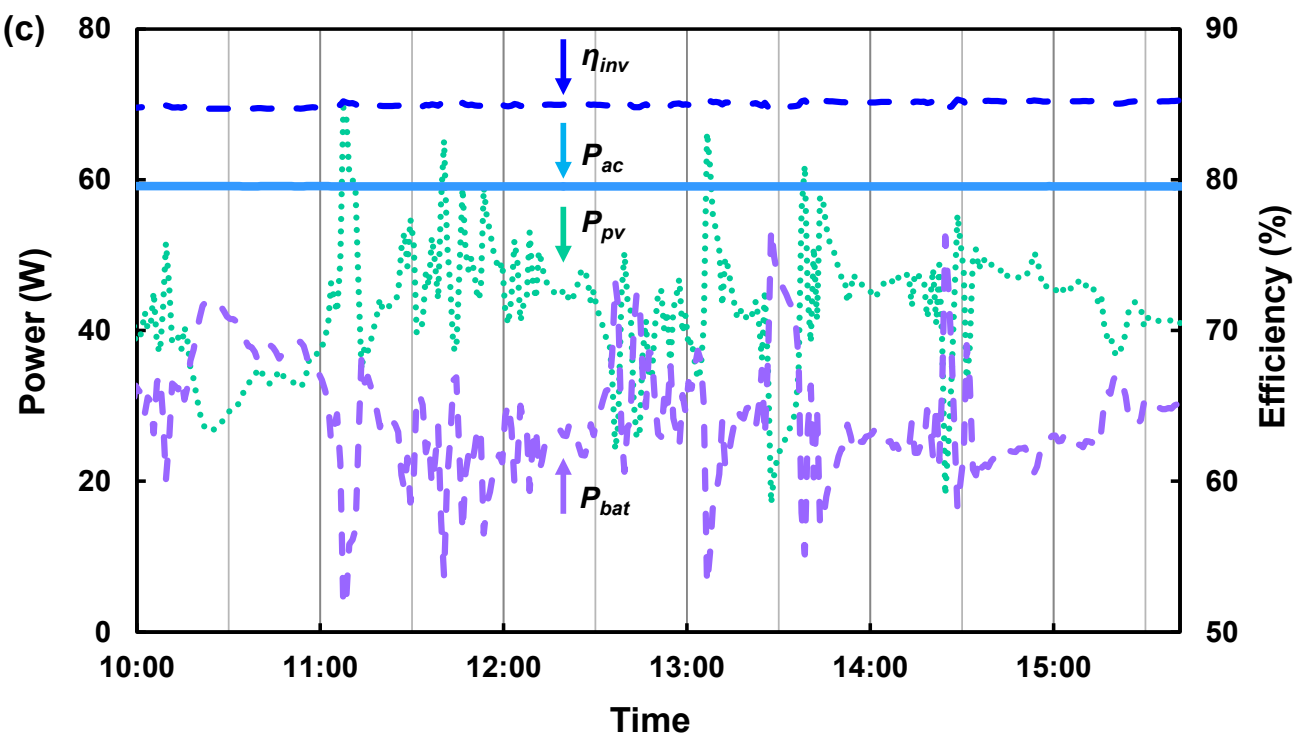

Figure 3. (a) Amount of solar radiation, (b) temperature/humidity, and (c) variation in conversion efficiency and powers during the measurements 


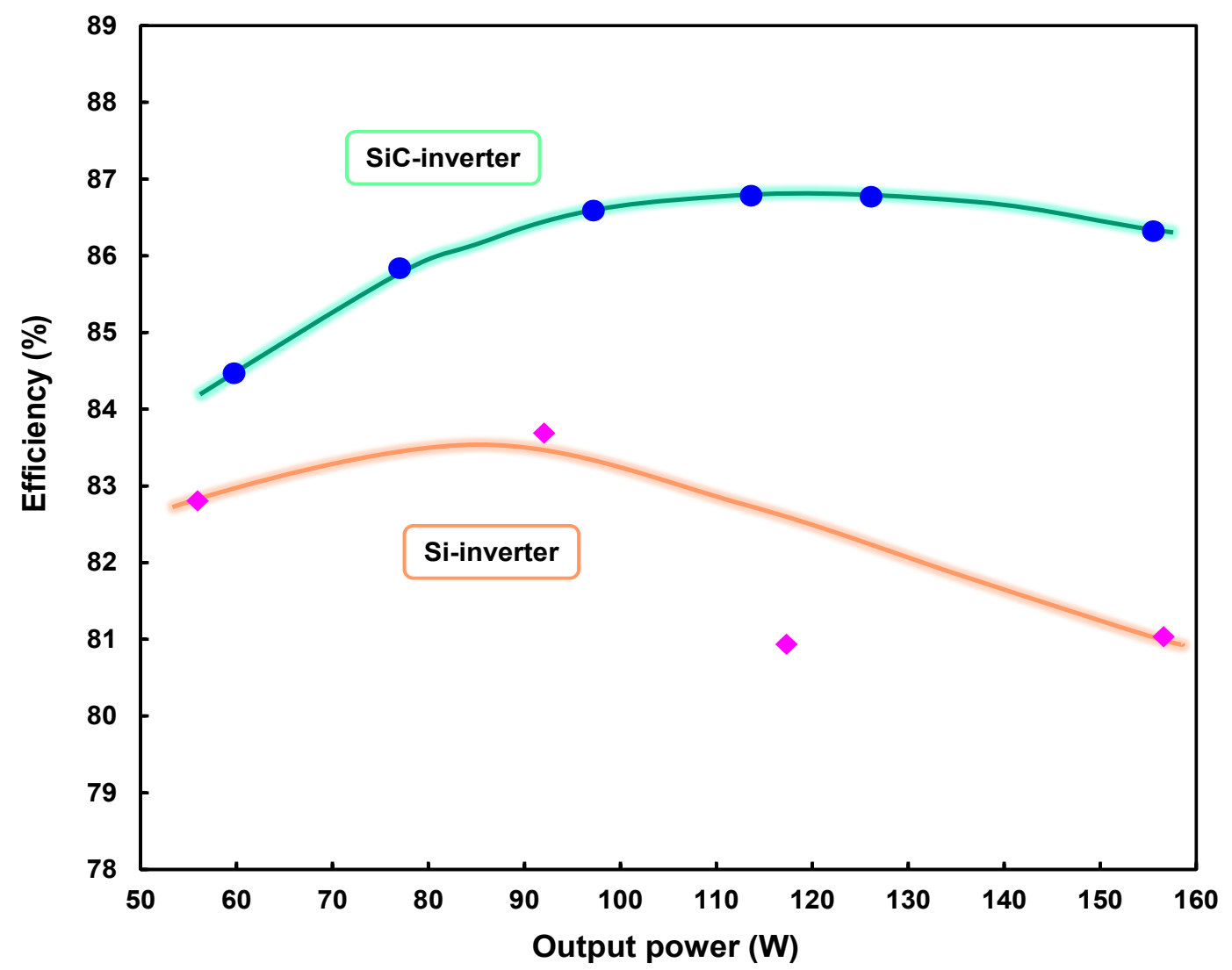

Figure 4. DC-AC conversion efficiency of SiC-FET and Si-FET inverters. The power was supplied by spherical Si solar cells.

Electric power loss in the inverters is strongly dependent on both conduction loss by the on-resistance and switching loss affected by accumulated carrier. In the present work, it is believed that the $R_{\text {on }}$ values were decreased by the SiC-FET by replacing Si-FET in the conventional inverter, which resulted in the improvement of conversion efficiency. As the output power increases, the difference in the conversion efficiency of the inverter with SiC-FET power devices and a conventional inverter with Si-FET increased up to $\sim 5 \%$ in the range of $120 \sim 150 \mathrm{~W}$, as observed in Fig. 4. More than 10 irradiation profiles were obtained for various output powers in Fig. 4. It is suggested that the effect of SiC-FET power devices become remarkable in the inverters as the output power increases.

In addition to improvement of the efficiencies, the stability of the efficiencies is obtained above $\sim 100 \mathrm{~W}$, as observed in Fig. 4. The efficiencies of Si-inverter decreased down to $\sim 81 \%$, which would be due to the heat generation. Heat generation of the present SiC-SBDs was not so much, and the SiC-SBD are also considered to be stable even at the elevated temperatures compared with the ordinary $\mathrm{Si}$ devices. The present electric circuit should be wholly optimized SiC-FET in the future work as portable devices.

\section{Conclusions}

A power storage system using spherical Si solar cells, lithium-ion battery and the inverter with SiC-FET/SBD equipped with a MPPT charge controller was constructed and evaluated, which were compared with an ordinary Si-based converter. The spherical Si solar cells were used as the power sources because of lighter and more flexible panels compared with the ordinary flat Si solar panels. The DC-AC conversion efficiencies of the spherical Si solar cells were improved by using the SiC-FET, which indicate the effectiveness of the $\mathrm{SiC}$ devices. When the output power of $\mathrm{SiC}$ inverter increased, the difference of DC-AC conversion efficiency of SiC-FET and Si-FET inverters increased up to $\sim 5 \%$. The efficiencies were still preserved even at the $\sim 150 \mathrm{~W}$, which would be due to the stability of SiC-SBD at the elevated temperatures. In addition, efficiencies of the inverters were not affected by fluctuation of charge condition of Li battery, and almost constant efficiencies were maintained. Furthermore, the size and weight of the SiC-inverter with the MPPT were reduced down to $1260 \mathrm{~cm}^{3}$ and $1.3 \mathrm{~kg}$, respectively, which is almost half size of the previous inverter system. The present $\mathrm{SiC}$-based inverter system combined with $\mathrm{Li}$ ion battery and spherical $\mathrm{Si}$ solar cells is expected as the emergency, portable power source with good efficiency under comparatively low electric powers of $\sim 150 \mathrm{~W}$.

\section{Acknowledgements}

This work was supported by Super Cluster Program of Japan Science and Technology Agency (JST). 


\section{REFERENCES}

[1] T. Maruyama, H. Minami, Light trapping in spherical silicon solar cell module, Solar Energy Materials and Solar Cells Vol. 79, 113-124, 2003.

[2] C. Okamoto, T. Minemoto, M. Murozono, H. Takakura, Y. Hamakawa, Defect evaluation of spherical silicon solar cells fabricated by dropping method, Japanese Journal of Applied Physics, Vol. 44, 7805-7808, 2005.

[3] M. Gharghi, H. Bai, G. Stevens, S. Sivoththaman, Three-dimensional modeling and simulation of $\mathrm{p}-\mathrm{n}$ junction spherical silicon solar cells, IEEE Transaction on Electron Devices, Vol. 53, 1355-1363, 2006.

[4] T. Minemoto, H. Takakura, Fabrication of spherical silicon crystals by dropping method and their application to solar cells, Japanese Journal of Applied Physics, Vol. 46, 4016-4020, 2007.

[5] Z. Liu, A. Masuda, M. Kondo, Investigation on the crystal growth process of spherical Si single crystals by melting, Journal of Crystal Growth, Vol. 311, 4116-4122, 2009.

[6] T. Oku, M. Kanayama, T. Akiyama, Y. Kanamori, M. Murozono, Microstructure analysis and properties of spherical silicon solar cells with anti-reflection thin films, Physica Status Solidi C, Vol. 10, 1840-1843, 2013.

[7] T. Oku, M. Kanayama, Y. Ono, T. Akiyama, Y. Kanamori, M. Murozono, Microstructures, optical and photoelectric conversion properties of spherical silicon solar cells with anti-reflection $\mathrm{SnO}_{\mathrm{x}}$ : $\mathrm{F}$ thin films, Japanese Journal of Applied Physics, Vol.53, 05FJ03-1-7, 2014.

[8] Y. Shirahata, B. Zhang, T. Oku, Y. Kanamori, and M. Murozono, Microstructures and optical properties of silicon spheres for solar cells, Materials Transactions, vol. 57, 1082-1087, 2016.

[9] T. Nakamura, Y. Akashi, M. Murozono, Fabrication methods of spherical semiconductor particles, Japan Patent 2010-150106 (2010).

[10] Y. Kanamori, Y. Akashi, M. Murozono, Fabrication methods of crystal semiconductor particles, Japan Patent 2012-126592 (2012).

[11] M. Murozono, Y. Ohshima, T. Hibino, Fabrication methods of semiconductor particles, Japan Patent 2012-17234 (2012).

[12] B. Burger, D. Kranzer, O. Stalter, Efficiency improvement of PV-inverters with SiC-DMOSFETs, Materials Science Forum, Vol. 600-603, 1231-1234, 2008.

[13] X. Yaosuo, K. C. Divya, G. Griepentrog, M. Liviu, S. Suresh, M. Manjrekar, Towards next generation photovoltaic inverters, IEEE Energy Conversion Congress and Exposition, 2467-2474, 2011.

[14] U. Schwarzer, S. Buschhorn, K. Vogel, System benefits for solar inverters using $\mathrm{SiC}$ semiconductor modules, Power Conversion and Intelligent Motion Europe, (PCIM), 787-794, 2014.

[15] K. P. Thooyamani, V. Khanaa, R. Udayakumar, Level voltage inverter controlled with ISPWM, Middle-East Journal of Scientific Research, Vol. 20, 2059-2064, 2014.

[16] B. Burger, D. Kranzer, O. Stalter, Cost reduction of pv-converters with SiC-DMOSFETs, 5th International Conference Integrated Power Systems (CIPS), 1-5, 2008.

[17] H. Zhang, L. M. Tolbert, B. Ozpineci, M. S. Chinthavali, Power losses and thermal modeling of 4H-SiC VJFET inverter, IEEE Industry Applications Society Annual Meeting, 2630-2634, 2005.

[18] A. Hensel, C. Wilhelm, D. Kranzer, Development of a boost converter for PV systems based on SiC BJTs, 14th European Conference on Power Electronics and Applications, (EPE 2011).

[19] L. Li, C. Li, Y. Cao, F. Wang, Recent progress of SiC power devices and applications, IEEJ Transaction on Electrical and Electronic Engineering, Vol. 8, 515-521, 2013.

[20] D. De, A. Castellazzi, A. Solomon, A. Trentin, M. Minami, T. Hikihara, An all SiC MOSFET high performance PV converter cell, 15th European Conference on Power Electronics and Applications (EPE 2013) 1-10, 2013.

[21] C. Sintamarean, E. Eni, F. Blaabjerg, R. Teodorescu, H. Wang, Wide-band gap devices in PV systems- opportunities and challenges, International Power Electronics Conference 1912-1919, 2014.

[22] T. Oku, T. Matsumoto, K. Hiramatsu, M. Yasuda, A. Shimono, Y. Takeda, M. Murozono, Construction and characterization of spherical Si solar cells combined with $\mathrm{SiC}$ electric power inverter, AIP Conference Proceedings, Vol. 1649, 79-83, 2015.

[23] T. Oku, T. Matsumoto, K. Hiramatsu, M. Yasuda, Y. Ohishi, A. Shimono, Y. Takeda, M. Murozono, Construction and evaluation of photovoltaic power generation and power storage system using $\mathrm{SiC}$ field-effect transistor inverter, AIP Conference Proceedings, Vol. 1709, 020024-1-10, 2016.

[24] T. Matsumoto, T. Oku, K. Hiramatsu, M. Yasuda, Y. Shirahata, A. Shimono, Y. Takeda, M. Murozono, Evaluation of photovoltaic power generation system using spherical silicon solar cells and SiC-FET inverter, AIP Conference Proceedings, Vol. 1709, 020023-1-6, 2016. 